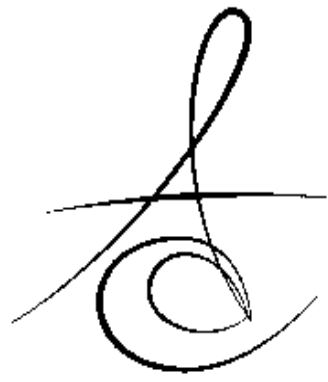

Makale Kodu/Article code: 3171

Makale Gönderilme tarihi: 02.12 .2016

Kabul Tarihi: 29.03.2017

\section{DİJİTAL DENTAL FOTOĞRAFÇILIK-II}

\author{
DIGITAL DENTAL PHOTOGRAPY-II
}

Prof. Dr. Funda BAYINDIR* Arş. Gör. Dt. Berkman ALBAYRAK* öz

Diş hekimliğinde fotoğraf çekimi vakaların yayınlanmasında, arşivlenmesinde, renk seçiminde, bilgi ve görüntünün laboratuvar ortamına aktarılmasında, teşhis ve tedavi planlamasında ve hukuki davalarda delil olarak kullanılmaktadır. Ayrıca, adli tıbbı ilgilendiren olgularda dental fotoğraf, kimlik tespitinde röntgenlerle beraber en az parmak izi kadar önemli rol oynar. Günümüz estetik diş hekimliğinde dijital iş akışının ilk basamağını standardize dental fotoğrafların bilgisayar ortamına aktarıması oluşturmaktadır. Uygun çekim standartları ile hem tedavi öncesi hem de tedavi sonrası ekstra-oral ve intra-oral alınan bu fotoğrafların hekimin arşivinde bulunması mesleki geçmiş açısından da oldukça önemlidir. Tedavi sonrasında alınan fotoğraflarla tedavinin yüzde meydana getirdiği değişimler de fotoğraflanmalıdır. Bu makale ekstra-oral ve intra-oral fotoğrafların çekimi sırasında dikkat edilecek konuları ve makina ayarları hakkında klinik kullanım için gerekli bilgiyi mevcut literatür ışığında sunmaktadır.

Anahtar Kelimeler: Dental fotoğrafçlık, Digital Single Lens Refleks (DSLR), dijital fotoğraf makinesi, makro çekim

\section{GİRIŞ}

DSLR olarak da bilinen dijital SLR kameralar, objektiflerinin değiştirilebilir olması ve kullanıcıya farklı objektiflerle farklı sonuçlar alma olanağı sağlaması nedeniyle medikal ve dental fotoğrafların çekiminde kullanılması önerilen makinalardır. ${ }^{1-6}$ Dental fotoğrafların çekiminde DSLR kameralarla $60 \mathrm{~mm}, 85 \mathrm{~mm}$ ve $105 \mathrm{~mm}$ lensler ${ }^{4}$ ve dental makro çekimler için

\section{ABSTRACT}

In dentistry, dental photographs of cases are used in publishing the cases, in archiving them, choosing the color, transferring the information and the images to the laboratory and planning the diagnosis and the treatment, as well as legal evidence. In addition, dental photographs play an important role with x-rays in identification as much as the fingerprints. In recent aesthetic dentistry, transferring standardized dental photographs on a computer is the first step of digital workflow. In terms of a successful career, it is really important for a dentist to keep in the archive the extra-oral and intra-oral photographs taken in appropriate shooting standards before and after the treatment. Post-treatment photographs are supposed to display the changes made by the treatment on the face. This article aims to present the issues that have to be taken into consideration and the necessary information about camera settings in the light of current literature during taking the extra-oral and intra-oral photographs.

Key words: Dental photography, Digital Single Lens Reflex (DSLR), digital camera, close-up (dairesel) flaşlar kullanılmaktadır . Dental fotoğraf çekimi için kullanılan kameralar ve ayarları, makine markası ve objektif türüne göre farklılık göstermektedir $^{7}$ (Tablo 1,2). Fotoğraflar, kapsamlı tedavi planının bir parçası olmalıdır. Teşhis ve tedavi planlaması, eğitim, hasta motivasyonu, vaka sunumu, laboratuvarla iletişim, sigorta ve halkla ilişkiler açısından dental fotoğraflar önemli bir yer tutmaktadır. ${ }^{8-15}$

${ }^{*}$ Atatürk Üniversitesi Diş Hekimliği Fakültesiprotetik Diş Tedavisi AD, Erzurum. 
Fotoğraf çekimine geçmeden önce hasta hazırlığı yapılmalıdır.

Tablo 1. Intra-oral fotoğraflar için önerilen DSLR kameralar ve ayarları

\begin{tabular}{|c|c|c|c|}
\hline Kamera & $\begin{array}{c}\text { Nikon DSLR } \\
\text { (Nikon corp. } \\
\text { Japan) }\end{array}$ & $\begin{array}{c}\text { Canon DSLR } \\
\text { (Canon Inc. Japan) }\end{array}$ & $\begin{array}{c}\text { Nikon DSLR } \\
\text { (Nikon corp. } \\
\text { Japan) }\end{array}$ \\
\hline Flaş & Nikon R1C1 & $\begin{array}{c}\text { SigmaRingFlaş/Can } \\
\text { on RingFlaş }\end{array}$ & Sigma Ring Flaş \\
\hline $\begin{array}{c}\text { Power } \\
\text { setting }\end{array}$ & TTL & eTTL & $1 / 4$ \\
\hline $\begin{array}{c}\text { Aperture } \\
\text { value/F }\end{array}$ & $\mathrm{F} 22$ & $\mathrm{~F} 25$ & $\mathrm{~F} 25$ \\
\hline $\begin{array}{c}\text { Shutter } \\
\text { speed/S }\end{array}$ & $1 / 160$ & $1 / 125$ & $1 / 160$ \\
\hline
\end{tabular}

Tablo 2. Lens üzerinde $90^{\circ}$ lik açı ile twin (ikiz) flaş ile farklı lenslerle objeye olan uzaklık miktarları: Odak uzaklığı çarpanı (Crop faktör) : 1.6

\begin{tabular}{|l|l|l|l|}
\hline Büyütme oranı & $1: 1$ & $1: 2$ & $1: 3$ \\
\hline Nikon $60 \mathrm{~mm}$ & 5 & 10 & 15 \\
\hline Nikon $85 \mathrm{~mm}$ & 14,5 & 29 & 43,5 \\
\hline Nikon $105 \mathrm{~mm}$ & 14,8 & 29,6 & 44,4 \\
\hline
\end{tabular}

\section{Hasta hazırlığı}

- Hasta koltukta rahat bir şekilde oturmalı ve tüm işlem hastaya aktarılmalıdır.

- Hasta hizasından biraz yukarıda olacak şekilde hekim sandalye yüksekliği ayarlamalı ve hastadan gerekirse kafasını eğmesi, sağa-sola çevirmesi istenir.

- Eğer dudak ekartasyonunu hasta yapacaksa, hastaya eldiven giydirilmelidir.

- Hasta doğal ve rahatlamış şekilde gülümsemelidir. Merkezde hastanın burnu konumlandırımalıdır. Kamerayı doğru pozisyona getirmek için interpupillar çizgi ve vertikal orta hat rehber olarak kullanılmalıdır.

\section{Arka plan, malzeme ve intraoral bölgelerin hazırlığı}

- Tedavi öncesi ve sonrası fotoğrafların hepsinde hastanın arkasında uygun bir arka plan kullanılmalıdır.

- Fotoğraflanacak bölgenin debris, kan, tükürük, hava kabarcığı, siman, ölçü materyali ve eldiven pudrasından arındırılmış olması gerekmektedir.

- Uygun bir fotoğraf için simetrik bir şekilde gerekli ekartasyon yapılmalı.
- Yüksek kaliteli ağız aynaları ve koyu spatüller kullanarak dudakların ön dişleri kapaması önlenmelidir (Resim1).

- Lateral, palatal ve okluzal görüntüler için kullanılacak aynalar rodyum içerikli olmalıdır.

- Buğulanmayı önlemek için ayna sıcak suya koyulmalı ve ardından pamuk/kağıt havluyla veya hava spreyi ile hafifçe kurulanmalı.

- Koyu arka planlar, dişlerin translusent bölgelerini ve restorasyonları görüntülemede daha iyi bir kontrast yakalanması amacıyla kullanılmalı (Resim 2-3).

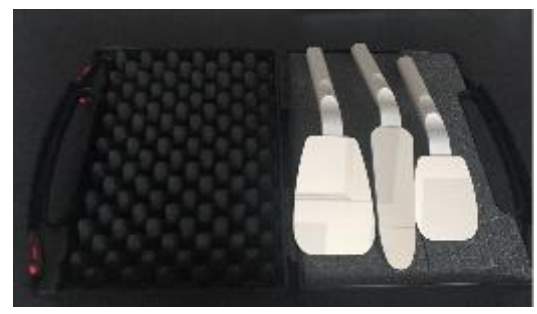

Resim 1. Dental fotoğraf çekimleri için özel aynalar

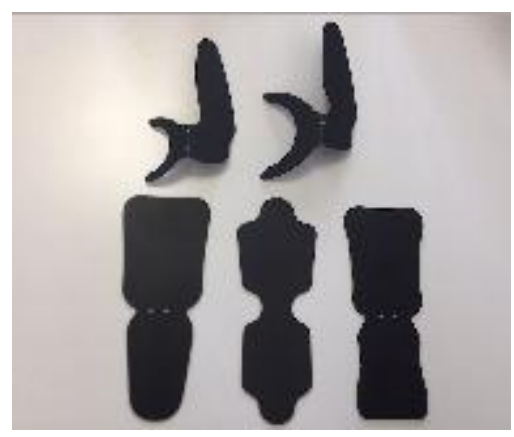

Resim 2. Kontrast plaklar

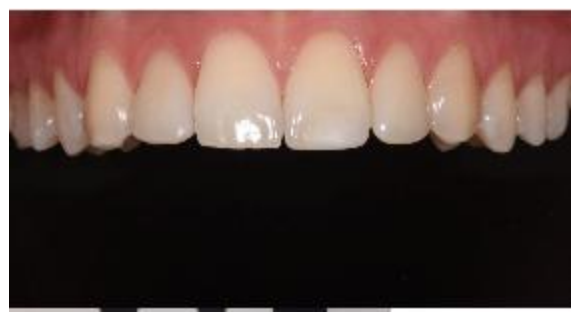

Resim 3. Kontrast plak ile üst çene çekimi

\section{Kamera ve diş hekiminin hazırlığı}

- Yüksek bir alan derinliği için diyaframı küçültülmeli ve büyütme oranı 1:1 olarak ayarlanmalıdır. 
- Dişler fotoğrafta doğru aksiyal açıda konumlanmalıdır.

- Maksillar kesicileri görüntülerken burun ve bıyık fotoğrafa dahil edilmemelidir.

- Dişleri fotoğraflarken hastanın dilini geride tutmasını istenir veya asistan yardımı ile ekarte edilir.

- Daha kaliteli bir görüntü için ayna kenarlarını, parmakları ve aydınlatılmamış olan dişleri fotoğraftan kırpılabilir.

- Çekim şartları (ışık, makine ayarları, hasta pozisyonu) standardize edilerek, farklı aralıklarla farklı kişiler tarafından çekilmiş fotoğrafları karşılaştırmak mümkün olur.

- Oral kavite için otofokus kullanılmamalı, çekim modu Manuel (M) fokus olarak kullanılmalıdır

- Flash modu: eTTL

- ISO: 200

- Beyaz ayarı: Flash

- Görüntü kalitesi: Büyük JPEG, renk skalası içinse RAW

- Enstantane: 1/250

- Diyafram: Tüm yüz görüntüsü için $1 / 8$, intraoral görüntü için 1/32 olarak ayarlanmalıdır. ${ }^{16-19}$

Hasta, hekim ve kamera ayarlarına ait hazırlıklar tamamlandıktan sonra tüm yüz, profil ve ağız içi fotoğrafların çekimine geçilebilir.

1-Tüm yüz ve profil fotoğrafları ${ }^{5,20-22}$

Ekstra oral tüm yüz fotoğrafları özel aydınlatma ekipmanları ile özel olarak hazırlanmış bir stüdyo ortamında veya uygun bir arka fon ayarlanmış klinik ortamında yapılabilir. Özellikle ortodontik, maksilofasial veya restoratif tedavilerin yüzde oluşan değişimleri göstermek amacıyla kullanılırlar. Alınan fotoğraflarda yüzdeki herhangi bir kırışıklık veya fasial bir defekt varsa tedavi öncesi kaydedilmelidir (Resim 4).

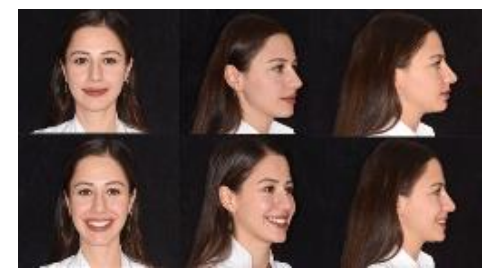

Resim 4. Farklı pozisyonlarda alınmış portre fotoğrafları

\section{Dental portre kurulumu}

Fasiyal fotoğraf veya portrelerin kurulumu; doğal gün ışı̆̆, bilateral kamera takılı flaşlar ve stüdyo flaşları olmak üzere 3 farklı aydınlatma yöntemi kullanılarak gerçekleştirilir.

Aşağıda bazı öneriler yer almaktadır:

- İstirahat halinde frontal yüz görüntüsü

- Gülümseme esnasında frontal yüz görüntüsü (insizal düzlemin interpupillar hat ile ilişkisinin değerlendirilmesi)

- Abartılı gülme esnasında frontal yüz görüntüsü (maksillar gingival dokuların değerlendirilmesi)

- İstirahat halinde portre (örneğin; ortodontik değerlendirme, dudak pozisyonları)

- Gülümseme esnasında portre (maxillar kesicilerin eğimlerinin değerlendirilmesi)

- Abartılı gülme esnasında portre

- Frontal bütün yüz görüntüleriyle aynı pozlarda alınan dentofasiyal görüntüler (sadece dudaklar ve dişleri dâhil ederek) ${ }^{21}$

\section{Doğal gün ışığı kurulumu}

Birkaç detay gerektiren bu kurulum oldukça basittir:

- Arka planda siyah veya isteğe bağlı olarak seçilen bir renkte kıyafet veya kart,

- Bir metre karelik beyaz, gümüş veya altın reflektörler,

- Bulutlu ve az ışığın olduğu bir günde daha yavaş bir enstantane ve daha geniş bir diyafram kullanımı için bir tripod kullanılmalıdır.

\section{Bilateral kamera takılı flaşlar}

İkinci bir seçenek de kamera takılı flaş olarak ring flaş veya bilateral flaş kullanımıdır. Bu kurulumun avantajları yer kaplamayıp ucuz olduğu gibi kolay ve etkili olmasıdır. Ancak, ring ve bilateral flaşların yoğunluğu yüzü aydınlatmak için yeterli değildir; daha geniş bir diyafram ve yavaş enstantane hızı seçilerek doğru poz yakalanabilir. Renkli arka planlar kullanıldığı takdirde objenin başının arkasında rahatsız edici gölgeler oluşabilir.

\section{Stüdyo flaşları}

Stüdyo flaşları, yüksek kaliteli portreler için oldukça sık kullanılan, ideal ve standart görüntü kalitesi sağlayan flaşlardır. Stüdyo kurulumu için 4 metre karelik bir alanın ayrılmış olması gerekir ve bu alan ayrı bir odada olabileceği gibi klinik, bekleme salonu, resepsiyon gibi alanlarda da oluşturulabilir. Basit bir stüdyo kurulumu için gerekli olan malzemeler şunlardır:

- İki veya üç elektronik stüdyo flaşı

- Işık kaynağını daha geniş hale getirip,

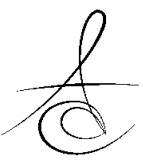


sonrada ışığı dağıtarak daha yumuşak gölgeler elde edilmesini sağlamak için soft box veya yansıtan şemsiyeler

- Flaş aksesuarları: flaş üzerinde belirli alanın ışı̆ını kesmeye yarayan ayarlanabilir siperler; barn door

- Reflektör (beyaz, gümüş veya altın)

- Arka plan için renkli kumaş veya kartlar. ${ }^{5,21}$

- Frontal-profil görünüm elde edilir.

- 1:10 büyütme ile çekilmeli

- Dudaklar ekarte edilmemeli

- Arka fonda gölge oluşumunu engellemek için siyah veya gri fon kullanılmalı

- İnter-pupiller çizgi fotoğrafın üst kenarına paralel olmalı

- A/Av modunda f 8

- Enstantene 1/125 2,20,22

2-Gülümseyiş 20

Her türlü kozmetik çalışma için gereklidir. Hastanın diş etlerini mümkün olduğunca fazla gösterecek şekilde gülümseme sağlanmalı ve maksimum alan derinliği için kaninler üzerine odaklanma yapılmalıdır. Lateral gülüş görüntüsü için üst laterallere odaklanılmalıdır. 1:2 büyütme oranı kullanılmalıdır (Resim 5).

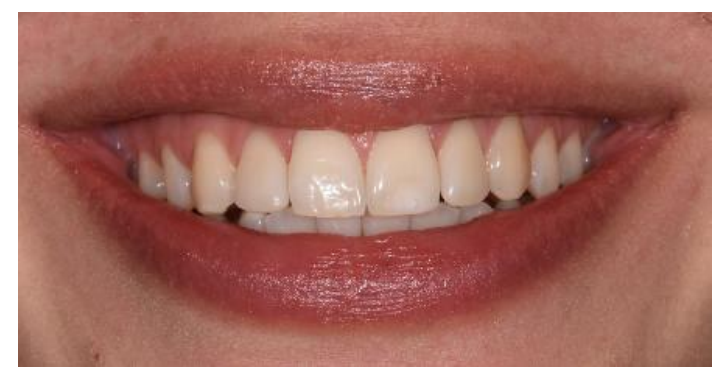

Resim 5. Gülümseme fotoğrafı

\section{3- Dudaklar retrakte, dişler sentrik oklüzyon durumunda ${ }^{5,23}$ \\ Dudak ekartörü kullanarak yumuşak dokuyu} dişlerin bukkal yüzlerinden yukarı-dışarı yönlerde kaldırılmalıdır. Odağı lateral dişler üzerine ayarlamak, bütün dişleri kabul edilebilir bir odak aralığında kapsayacak uygun bir alan derinliği elde etmeye yardımcı olur. Oklüzal düzlemi vizörün en üst ve en alt kenarlarına sığacak şekilde horizontal düzlemde tutulmaya çalışılmalıdır. Ancak, yine de dijital fotoğraflarda hizalama hatası varsa sonradan düzenleme programları ile ayarlanabilir.
İnterkuspal pozisyonun bir fotoğrafının alınmasının ardından hastanın istirahat pozisyonuna gelmesini sağlayıp ikinci fotoğraf alınmalıdır. Ön çekimde lateral dişler, yan çekimlerde kanin dişleri ve premolarların ortasına odaklama yapılmalıdır. ${ }^{5,7}$

\section{durumda \\ 4) Dudaklar retrakte, dişler hafif açık}

Posteriorda yaklașık bir parmak kalınlığında açıklık verilir.

5) Dudaklar retrakte durumda yakın (Close-up) çekim

- Sağ, sol ve ön cepheden çekim yapılır

- Frontal-profil görünüm elde edilir

- $1: 1$ büyütme ile çekilmeli

- Dudaklar ekarte edilmemiş olmalı

- Arka fonda gölge oluşumunu engellemek için siyah veya gri fon kullanılmalı

- Inter-pupiller çizgi fotoğrafın üst kenarına paralel olmalı $^{22}$

Ön dişlerin fotoğraflarında arka plan genellikle gözlemcinin dikkatini dağıtmaktadır. Bu problem, arka planda uniform bir karanlık alan yaratıp dişlerin kontrastını arttırmaya yarayan, çeşitli şekillerde bulunabilen ve otoklava girebilen mat koyu metal koruyucuya sahip kontraktörlerin yardımıyla elimine edilebilir (Resim 6).
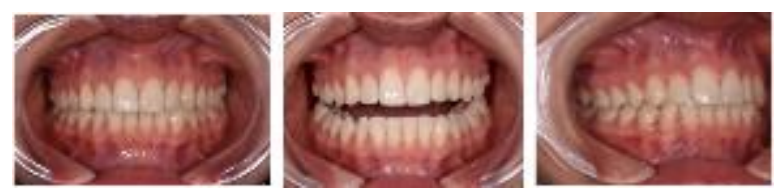

Resim 6. Dudaklar retrakte olarak alınan ağız içi fotoğraflar

\section{6) Lateral görüntü $5,20,23$}

Lateral görüntüler hem aynalı hem de aynasız alınabilir. Aynasız görüntü alınacağı zaman, üst ve alt dudaklar arasında dar açılı bir dudak retraktörü kullanmak daha uygundur. Bu şekilde 2. ve 3. molara kadar bukkal yüzeyler açıkça görüntülenebilmektedir.

Lateral görüntüler için ayna kullanılacağı zaman, ayna yerleştirilirken öncelikle hastaya rahatlamasını söylenir. Böylece, yanaklar dışarı doğru çekilerek alan oluşturulur ve ayna ile kamera arasında daha iyi bir açı sağlanır. Aynanın lingual konumunun öğürme refleksini tetikleyebileceği unutulmamalıdır. Hastadan dilini serbest bir şekilde ağzın

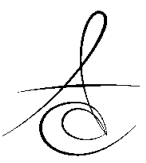


ortasında bırakması söylenerek sulkusta ayna için daha fazla yer sağlanabilir (Resim 7).

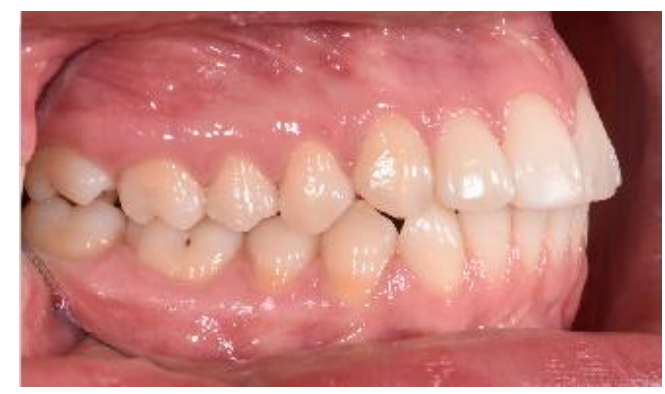

Resim 7. Bukkal ayna ile ağız içi lateral çekim

\section{7) Okluzal çekim 2,5,20}

Okluzal görüntü, ağız aynası kullanımını gerektirir. Yumuşak dokuları dişlerin bukkal yüzlerinden uzaklaştırmak için dudak ekartörleri kullanımalı ve odak birinci premolara ayarlanmalıdır. Aynalarda buğu olmadan çekim yapılmalıdır. İkinci ve üçüncü molar görüntülerini alabilmek için ayna ağız içerisinde konumlandırıırken öğürme refleksi gelişebilir, bulantıyı azaltabilmek için radyografi ve ölçü alımındaki önlemler alınabilir. Bu problem olacaksa, ayna sadece ilgili bölgeyi gösterecek şekilde konumlandırılır, ancak bu durumda geri kalan okluzal alan fotoğrafta çıkmayacaktır. ${ }^{5}$ Maksillayı fotoğraflamak için, hastanın başını geriye doğru eğerek saat 12 pozisyonunda (Resim 8); mandibulayı fotoğraflamak içinse, saat 9 pozisyonunda (Resim 9) ve hastanın üzerinden hastaya doğru eğilerek çekim yapılmalıdır. Fotoğrafta mümkün olduğunca fazla diş görüntü içine alınmalı, burun kadraja alınmamalıdır.

Alt çene arkının görüntülenmesi sırasında insizal dişlerin vestibül kenarları fotoğraf karesi içinde olmalı ve dil, dişlerin üzerine gelerek görüntüyü engellememelidir. Fotoğraf makinesi ile ayna arasındaki açı, 45 derece olmalı ve $1: 2$ büyütme oranı kullanılmalıdır (Resim 10,11).

\section{Renk skalası fotoğrafları}

Dişlerin renk tonu karşılaştırmalarını sadece fotoğraflarla yapmak olanaksızdır; aynı zamanda gözle ve renk seçim cihazları kullanılarak yapılmalıdır. Yine de renk skalası analizlerinin fotoğrafla yapılması, teknisyenin süreci değerlendirmesi ve beyazlatma değerlerini takibi açısından da önem teşkil eder.

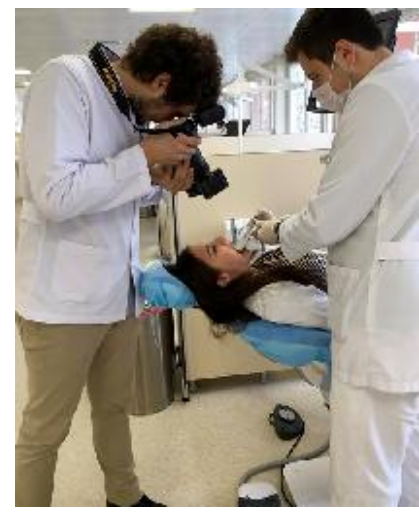

Resim 8. Üst çene okluzal çekim

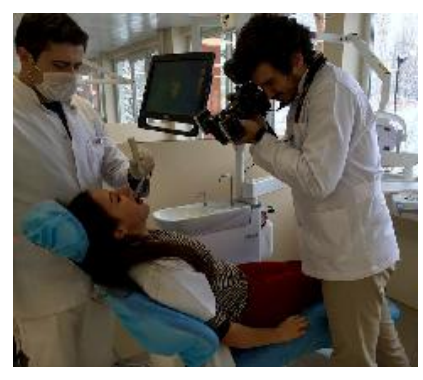

Resim 9. Alt çene okluzal_çekim

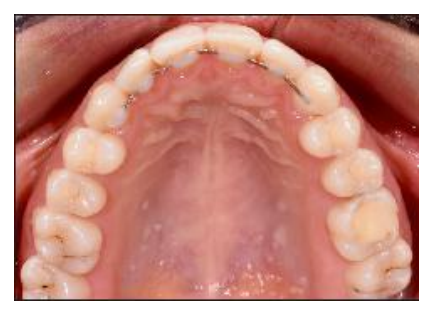

Resim 10. Üst çene; ayna ile okluzal çekim

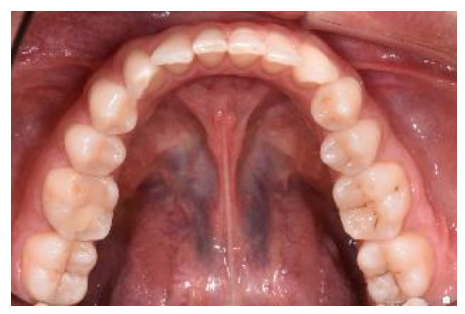

Resim 11. Alt çene; ayna ile okluzal çekim

Renk skalası fotoğrafların bilateral flaş aydınlatmasıyla yapılmalıdır. Oral mukoza için gri karton kullanılmalıır. Dişlerin tamamen kurutulmayıp hafif 
nemli olması gereklidir; özellikle rubber dam kullanımı yanlış renk tonu belirlemesine neden olabilir. Nem kontrolü önemlidir; ancak tükürüğün dişler üzerinde kalmasına izin verilerek oral kavitenin doğal haliyle görüntülenmesi sağlanabilir. Hastadan genel bir değerlendirme için tüm renk skalasını veya spesifik bir renk tonunu tutması istenebilir. Beyazlatma (Bleaching) derecesinin değerlendirmesi, renk tonlarının renk skalasından incelenmesi ile gerçekleştirilebilir. Daha net bir renk tonu analizi için renk skalasından belirli bir renk restorasyon yapılacak dişin yakınında tutulabilir. İdeal olarak, renk tonu seçimi diş kesimi öncesinde gerçekleştirilmelidir (Resim 12).

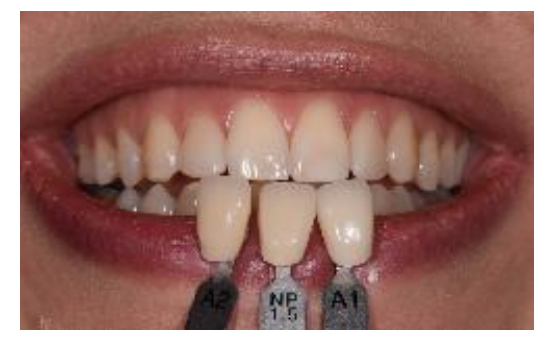

Resim 12. Fotoğraflarla renk seçimi

Eğer doğal dişlerin rengi, standart renk skalasındaki renklerin hiçbirine uymuyorsa hastaya özel bir renk tonu seçilmelidir. Eğer geleneksel renk skalalarındaki renklerle fotoğraf almak zorsa, ışıklandırmayla birlikte fotoğraf alınabilir. Bu metamerizmi engelleyerek daha uygun bir renk eşleştirmesi sağlayacaktır. Ayrıca digital fotoğraflarda renklerin olduğundan farklı görünme problemini önlemek için renk düzeltme (Color Correction) programları da kullanılabilir. Bu fotoğraflar alınırken;

- $1: 3$ büyütme oranı kullanılmalı

- Renk skalasından hastanın diş rengine en yakın iki renk çeşidini dişe yaklaştırılmalı; biri açık ve diğeri koyu.

- Skala ağızdaki dişle aynı vertikal düzlemde tutulmalı

- Uygun renkteki örneği dişe aynı düzlemde olacak şekilde paralel yerleştirilmeli.

- Diş hafif nemli olmalı.

- Dilin dişin lingual kenarına temas etmediğinden emin olunmalı.

- Maksillar anterior dişlerin özelliklerini ve translusenliklerini ön plana çıkarmak için kontrast plak kullanılmalıdır. ${ }^{24-28}$

\section{Capraz enfeksiyon kontrolü}

Diğer fotoğraf çeşitlerinden farklı olarak, dental fotoğrafçוlıkta çapraz enfeksiyon kontrolü çok daha önemlidir. Dental prosedürler için geçerli olan çapraz enfeksiyon tedbirleri dental fotoğrafçlıkta da kullanılabilir. Fotoğraf malzeme ve aksesuarları için özel bir alan oluşturulması önerilmektedir. Tüm dental malzemelerin el ile temas yüzeyleri (kamera, lens, tripod, kablolar vb.), tek kullanımlık selofan kapla kaplanmalıdır. Yanak ekartörleri, üretici talimatlarına uygun bir şekilde sterilize edilmeli, mümkünse otoklava sokulmalıdır. Ağız içi aynalar yüzey dezenfektanı sıkılmış gazlı bezlerle silinmelidir. Lekelenmelere ve tamiri olanaksız hasarlara neden olmamak adına cerrahi alkolle temizlenmemelidir. Ayrıca tüm intra-oral fotoğraf yansıtıcıları ve arka plan kartonları kullanıldıktan sonra atılmalıdır. ${ }^{25}$

\section{Etik kurallar}

Hastaya ait fotoğraflar başka platformlarda paylaşılacaksa hasta bilgilendirilmeli ve hastanın yüzü bu fotoğraflarda görünecekse yazılı izninin alınmış olması gerekmektedir. ${ }^{23}$ Hastadan bilgilendirilmiş onam alınmamış ve hasta kimliğini ortaya çıkaran fotoğraflar kesinlikle yayınlanmamalıdır. $^{2}$

\section{SONUÇ}

Diş hekimliğinde oldukça sık kullanılan dental fotoğrafların ışık şartları, büyütme oranları, hasta pozisyonu ve makina ayarları standardize edilmiş olarak alınması, farklı zaman aralıklarında farklı kişiler tarafından alınan fotoğrafların karşılaştırılması açısından oldukça önemlidir. Hekimin düzenli bir arşiv oluşturabilmesi için belli açılardan alınmış fotoğraflar, hasta dosyasında gerekli olduğunda kullanılmak için saklanabilir (Resim 13).

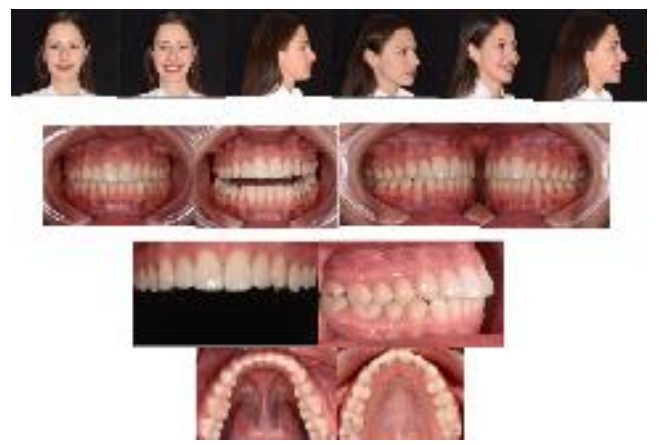

Resim 13. Ağız dışı ve ağız içi dental fotoğraflar 
Funda Bayındır: ORCID ID: 0000-0001-5699-2879 Berkman Albayrak: ORCID ID: 0000-0001-9002-2024

\section{KAYNAKLAR}

1. Ahmad I. Digital dental photography. Part 2: Purposes and uses. Br Dent J 2009; 9:206:45964.

2.Engin Ö. Dental Fotoğrafçlıı. Quintesence yayıncılık 2011;pp. 53-71.

3.Shagam J, Kleiman A. Technological updates in dental photography. Dent Clin North Am 2011; 55:627-33.

4. Lazar D, Cimpian S, Stratul S. An introduction of dental photography. A guide on specific cameras and accessories. TMJ 2011;1-2: 107-11

5. McLaren EA, Terry DA. Photography in dentistry. J Calif Dent Assoc 2001; 29:735-42.

6. Bayındır F. Dijital dental fotoğrafçılık-I. Atatürk Üniv Diş Hek Fak Derg 2015;25 434-40.

7. Patel A. Clinical digital dental photography. CAD/CAM 2012;3:6-10.

8. Mahn E. Clinical digital photography. Part 1: Equipment and basic documentation. International Dentistry-African Ed 2013; 3: 1826.

9. Dunn JR, Hutson B, Levato CM. Photographic imaging for esthetic restorative dentistry. Compend Contin Educ Dent 1999;20:766-8.

10. Terry DA, Snow SR, McLaren EA. Contemporary dental photography: Selection and application. Compend Contin Educ Dent 2008; 29:432-6.

11. Dunn J, Beckler G. Digital photography technology offers unique capabilities, advantages, and challenges to dental practices. J Calif Dent Assoc 2001;29:744-50.

12. Haak R, Schirra C. Dental photography in support of patient documentation and communication. Quintessence Int 2000; 31:649-57.

13. McLaren EA, Schoenbaum T. Digital photography enhances diagnostics, communication, and documentation. Compend Contin Educ Dent 2011;32:4,36-8.

14. Bengel W. Digital photography in the dental practice-an overview (II).Int J Comput Dent 2000; 3:121-32.

15. Ward $\mathrm{DH}$. The vision of digital dental photography. Dent Today 2007;26:104-5.

16. Desai V, Bumb D. Digital dental photography: a contemporary revolution. Int J Clin Pediatr Dent
2013;6:193-6.

17. Ahmad I. Digital dental photography. Part 3: Principles of digital photography. Br Dent J 2009; 23;206:517-23.

18. Ahmad I. Digital dental photography. Part 6: Camera settings. Br Dent J 2009;207:63-9.

19. Ahmad I. Digital dental photography. Part 5: Lighting Br Dent J 2009;11;207:13-8.

20. Christensen GJ. Important clinical uses for digital photography. J Am Dent Assoc 2005;136:77-9.

21. Ahmad I. Digital dental photography Part 7: Extraoral set-ups. Br Dent J 2009;207:103-10.

22. Ergin U. Photography in Medicine and Oral mucosa. Türkderm-Deri Hastalıkları ve Frengi Arşivi Dergisi 2012; 46: 150-6.

23. Sharland MR. An update on digital photography for the general dental practitioner. Dent Update 2008; 35:398-400, 402-4.

https://www.ncbi.nlm.nih.gov/pubmed/18717102

24. Ahmad I. Digital dental photography Part 1: An overview. Br Dental J 2009;206 :403-7.

25. Ahmad I. Digital dental photography. Part 8: Intraoral set-ups. Br Dent J 2009;207: 22 2009; 1517.

26. Wee AG, Lindsey DT, Kuo S, Johnston WM. Color accuracy of commercial digital cameras for use in dentistry. Dent Mater 2006; 22:553-9.

27. Griffin JD Jr. Excellence in photography: Heightening dentist-ceramist communication. Dent Today 2009;28:124-7.

28. Weston JF, Haupt E. Creating aesthetic success through proper clinician and laboratory technical communication. Dent Clin North Am 2011; 55:371-82.

\section{Yazışma Adresi}

Prof. Dr. Funda BAYINDIR

Atatürk Üniversitesi

Diş Hekimliği Fakültesi

Protetik Diş Tedavisi AD.

ERZURUM

TIf: +90 $4422360944-1751$

Fax: +90 4422360945

E-mail: fundabayindir(C)gmail.com 